\title{
A LEI DOS HOMENS: FORMAÇÃO JURÍDICA E CULTURA POLÍTICA NO BRASIL IMPÉRIO
}

\author{
LA LEY DE LOS HOMBRES: FORMACIÓN JURÍDICA Y CULTURA POLÍTICA EN EL \\ BRASIL IMPERIO
}

THE LAW OF MEN: JUDICIAL FORMATION AND POLITICAL CULTURE IN THE BRAZILIAN EMPIRE

\section{LA LOI DES HOMMES : FORMATION JURIDIQUE ET CULTURE POLITIQUE DU BRÉSIL IMPÉRIAL}

\author{
DOI: $\underline{10.5533 / 1984-2503-20113307}$
}

Vanessa Spinosa

\section{RESUMO}

O artigo busca relacionar a formação dos cursos jurídicos no Brasil com a estruturação política e intelectual que os estadistas do jovem país tentaram implementar com o intuito de ordenar a administração do poder. As leis, nesse sentido, foram ao mesmo tempo o ponto de apoio para que a gestão estatal ganhasse legitimidade e o reflexo de uma cultura política que se equilibrava entre o passado luso e um novo presente. Portanto, contemplando esse eixo de estudo, se pretende a atualização das discussões da história e do direito visando fortalecer os debates em torno do argumento da herança lusa após a independência brasileira.

Palavras-chave: cursos jurídicos, administração pública, política.

\section{RESUMEN}

Este artículo tiene como objetivo relacionar la formación en los cursos jurídicos del Brasil con su estructuración política e intelectual, ambos procesos liderados por los estadistas del joven país independiente y orientados a ordenar la administración del poder imperial. En este sentido, las leyes serán el punto de apoyo fundamental de la gestión estatal y la garantía de la legitimidad de sus acciones. Al mismo tiempo, estas leyes reflejaban una cultura política que se equilibraba entre el pasado luso y el nuevo presente. Por tanto, por este camino, se pretende actualizar las discusiones entre la historia y el derecho con el objetivo básico de contribuir a los debates sobre los elementos de la herencia lusa que 
sobrevivieron a la independencia brasileña.

Palabras-clave: cursos jurídicos, política, administración pública.

\section{ABSTRACT}

This article aims to relate the formation of judicial courses with the political and intellectual structure that the statesmen of the young country attempted to implement to order the administration of power. The laws, in this sense, were both a point of support allowing public management to become legitimate, and the reflex of a political culture poised between its Lusitanian past and a new present. However, within this focus, the article also intends to update discussions on history and law and in turn strengthen debates on the Lusitanian inheritance in Brazil's independence.

Keywords: judicial courses, public administration, politics.

\section{RESUMÉ}

Cet article cherche à mettre en relation la mise en place des études juridiques au Brésil avec la structuration politique et intellectuelle que tentèrent de réaliser les hommes d'États du jeune pays dans le but d'ordonner l'administration du pouvoir. En ce sens, les lois ont en même temps constitué le point d'appui pour que la gestion étatique gagne en légitimité et le reflet d'une culture politique en équilibre entre le passé lusitain et un nouveau présent. À partir de cet axe d'étude, notre objectif est donc d'actualiser et d'alimenter les débats en histoire et en droit autour de la nature de l'héritage lusitain après l'indépendance brésilienne.

Mots-clés : études juridiques ; administration publique ; politique.

O ministro nos Negócios da Justiça, Francisco Diogo Pereira de Vasconcelos, em 1857, citava as reflexões do então Conselheiro Procurador da Coroa:

É da natureza das Leis, e uma de suas propriedades, a qualidade de serem concebidas, organizadas, e promulgadas não para o bem de um só caso em particular, mas para todos que ocorrerem na espécie por elas figuradas, razão porque nunca houve, não há, nem pode haver Lei alguma, que em certa e determinada hipótese não seja omissa, ou não seja injusta, já pelo sumo rigor, já pelo sumo favor. Sendo obra de homens e [?] e executadas pelos homens, está necessariamente sujeita a dois perigos, muitas vezes inevitáveis: 0 que provém de sua maior ou menor imperfeição, e o que resulta dos 
erros dos mesmos homens, quer por entendimento, quer por vontade; vindo portanto os homens a constituir privativa $e$ exclusivamente a única garantia, ou função, que se pode encontrar, tanto para a formação de boas Leis, como para sua melhor execução $(\ldots)^{1}$.

A citação acima relatada referia-se a uma decisão imperial acerca de um casocrime específico, mas pretendia ser um exemplo central para que a discussão sobre as penas e o rigor-função das leis do Império fosse destacada. O esforço do ministro que redigia a decisão do Imperador era o de ratificar a importância de seguir as leis, de acoplar a organização do Estado e a necessidade de se fazer justiça nas ações administrativas através de seus representantes. Em uma era de império das leis, a busca pela sua homogeneização pelos diversos rincões do país seria uma das máximas para a ordem estatal. Concomitantemente, fazer imperar as leis era também observar as possibilidades de sua debilidade.

Em busca dessa preocupação com os perigos, também chamado de erros dos homens, como apontava o conselheiro do Império do Brasil, é que esta pesquisa se situa. Se as boas leis tinham diretamente garantia nos homens, o que eles faziam em favor do Estado? Qual era a base necessária para que esses homens fossem capazes não somente de formar a legislação do Império do Brasil, senão também de executá-la? Exercer uma função de justiça para o Império era também estar sujeito a mesclar múltiplas vontades e um entendimento, isto é, ser um representante da lei era estar imerso em uma teia social e em uma cultura jurídica que orientava os passos que se devia seguir.

Nesse sentido, podemos buscar duas vertentes essenciais para o entendimento das práticas jurídico-políticas no Império do Brasil. Uma seria ir ao encontro das principais fontes de formação dos magistrados, bacharéis à época; e outra, perceber as práticas jurídicas desses homens que, como as leis, podiam ser imperfeitas. Dado que uma vertente complementa a outra, nesse artigo se privilegiará ressaltar as bases formativas desses homens da justiça, relacionando formação jurídica e política com a tradição lusa.

Parece inevitável que a formação jurídica dos brasileiros do Império estivesse estreitamente associada à formação lusitana. Uma vasta gama de historiadores do direito e da história esteve atenta a esta relação, buscando conectar a formação do Estado à

\footnotetext{
${ }^{1}$ RELATÓRIO DO MINISTERIO DA JUSTIÇA APRESENTADO A ASSEMBLEIA GERAL LEGISLATIVA (1858). Rio de Janeiro: Typ.Nacional.
} 
cultura jurídica herdada da matriz lusa. E faz todo o sentido. Em boa medida, as gerações formadas pela ainda metrópole lusa foram importantes figuras políticas no processo de emancipação política do Brasil. Até que o Império do Brasil tivesse seus próprios centros universitários e faculdades de Direito, muitos jovens de posses cruzaram o Atlântico em busca de um título de bacharel, de matemático, de engenheiro ou de médico. Como se sabe, não apenas em Coimbra. França e Inglaterra estiveram nas rotas transatlânticas para a formação superior ${ }^{2}$. Contudo, é certo, Coimbra e os cursos jurídicos seguiram como as opções mais viáveis. Ser advogado, portanto, apesar de não ser a única, era a escolha preferida porque viabilizava acesso a uma gama ampla de ofícios de governo. Um bacharel podia ser um executor da justiça, sim, mas não apenas isso. Conhecer as leis estatais era o primeiro passo para entender sua dinâmica e funcionamento e assim, poder atuar em diversos setores. Também, conhecer de leis era poder legislar e, com isso, atuar nos bancos legislativos do poder. Era preciso, como se pode subentender, ter posses para seguir os estudos, dentro ou fora do país. Também se faziam necessárias essas mesmas posses para ser considerado cidadão ou mesmo um deputado, senador ou presidente de província no Império. Todos estes pontos coordenados possibilitam entender a lógica que envolvia formação, produção legislativa e política no Brasil oitocentista ${ }^{3}$.

Para a boa execução das leis, como citava o Ministro Vasconcelos, era necessário que sua única garantia obtivesse preparo. Pelo menos num plano geral e teórico, desde a primeira legislatura, em 1826, os parlamentares no Brasil requereram para o novo país a formação de bacharéis como um elo fundamental na construção e organização imperial ${ }^{4}$. Essa atitude tinha suas justificativas. A primeira delas era a obviedade de que ao novo Estado, novas leis e, a novas leis, uma formação para o seu conhecimento. Mas essa atitude, essa lógica, não estava longe de seu esteio colonizador.

Ainda que em um país emancipado se tentasse rescindir com o passado ou com a dependência de séculos, não era possível romper com a força do tempo. Os anos de ordenação política, jurídica e de organização do judiciário não poderiam ser borrados

2 Dias, Maria Odila da Silva (1968). "Aspectos da llustração no Brasil". In Revista do Instituto Histórico e Geográfico Brasileiro, n. 278, Rio de Janeiro, p.105-170; Gauer, Ruth M. Chittó (2001). A Construção do Estado-Nação no Brasil, Curitiba: Juruá.

3 Uma visão mais aprofundada dos apontamentos sobre o tema está em Spinosa, Vanessa (2011). Uma Justiça para o Estado: formação jurídica e produção legislativa no Brasil do período tardo-colonial à Regência (1750-1841), Trabajo de Grado (História), Universidade de Salamanca.

4 Gauer (2001). Op. cit.; Slemian, Andréa (2006). Sob o Império das Leis: constituição e unidade nacional na formação do Império do Brasil (1822-1834). Tese (Doutorado em História) - Universidade de São Paulo, São Paulo; Silva, Mozart Linhares da (2003). O Império dos Bacharéis, Curitiba: Juruá. 
abruptamente. Como se sabe muito do passado luso foi transformado. Reeditou-se a estrutura do Poder Judiciário, e eliminou muitos dos órgãos judiciário-coloniais desenvolvendo uma estrutura mais centralizadora e condensada. Vale destacar também que os Códigos Criminal, do Processo Criminal e Comercial foram avanços no que diz respeito a esse intuito personalista da ordem jurídica e judiciária no jovem país. Contudo, as Ordenações Filipinas ainda vigeram durante todo o Império, os Estatutos dos Cursos Jurídicos de Pernambuco e São Paulo seguiram a cartilha dos Estatutos da Universidade de Coimbra, que vigoravam desde a época pombalina, e o Código Criminal do Império, apesar de seu caráter moderno e humanista inspirado em outros países ${ }^{5}$, tinha forte conexão com o Código Criminal do jurista luso Mello Freire ${ }^{6}$.

A formação, tanto para os da Lusitânia quanto para os do Brasil, era o caminho para agregar um corpo profissional habilitado e conhecedor das regras do Estado. Venâncio Filho pondera que o ano de 1827 podia ser considerado como “(...) o símbolo da independência cultural do Brasip', pois que configurava a representação da independência intelectual, agora direcionada para a realidade nacional desapegada da dependência de "(...) nossos concidadãos atravessar os mares, e à custa de despesas e outros sacrifícios ir aprender à Universidade de Coimbra"8. Mas, simultaneamente, admite que a necessidade expressa pelo Visconde de Cachoeira, autor dos Estatutos, de "(...) formar homens hábeis para serem um dia sábios magistrados e peritos advogados de que tanto se carece e dignos Deputados e Senadores para ocuparem os lugares diplomáticos e mais empregos do Estado"9, se tratava de um esforço magnânimo de um país que precisava de todo o aparato funcional e docente para promover tal empreitada.

De todas as maneiras, como afirma Dallari,

(...) alguns líderes políticos perceberam muito cedo que era necessário formar no Brasil uma elite intelectual e política, que tivesse sentimentos nacionalistas, conhecesse a realidade $e$

\footnotetext{
5 O humanismo oitocentista tinha perfil filantrópico e seus maiores expoentes saíram das matrizes americana, francesa e inglesa no que tange às reformas penais. Conferir: Perrot, Michelle (1989). Os excluídos da História: operários, mulheres e prisioneiros. Rio de Janeiro: Paz e Terra; Silva, Mozart Linhares da (1997). Do Império da lei ás grades da cidade, Porto Alegre: EDIPUCRS.

${ }^{6}$ As ideias do jurista serão de forte apoio aos elaboradores do Código no Império, tanto pela codificação criminal de 1786 sob reinado de D. Maria I, quanto pelas aulas na cadeira de História do Direito Pátrio, em Coimbra. Ver: Neder, Gizlene (2000). Iluminismo jurídico-penal luso-brasileiro: obediência e submissão, Rio de Janeiro: Freitas Bastos, 2ª edição, Revan, p. 148-160.

Venâncio Filho, Alberto (1973). "A Criação dos Cursos Jurídicos, símbolo da independência nacional”. In RBIHG, vol. 299, Rio de Janeiro: Departamento de Imprensa Nacional, abr/jun., p. 80.

8 Luis José de Carvalho e Melo. Sessão 27 de Agosto de 1823. In ANNAES DO PARLAMENTO BRAZILEIRO. Assembléa Constituinte.1823. Tomo 4. Rio de Janeiro: Typ. de H.J. Pinto, 1879, p. 165.

9 Conferir Venâncio Filho (1973). Op. cit, p. 31 e 36.
} 
pensasse as instituições em termos brasileiros. E pelo que sabiam da experiência de outros povos, os cursos jurídicos cumpriam esse papel $^{10}$.

Muito dessa tendência discursiva observada entre as reuniões da Assembleia de 1823 e 1827, denota essa valorização do estudo como artefato da construção da unidade por parte desses estadistas-intelectuais. José Martiniano de Alencar, deputado do Ceará, defendendo a necessidade da formação de universidades no Brasil, afirmava:

Precisamos, Sr. Presidente, de uma universidade, e já, como de pão para a boca, temos mui poucos bacharéis para os lugares da magistratura (...) temos igualmente necessidade de homens capazes para os empregos públicos, e até para entrarem nesta augusta assembléia e é indispensável que haja onde eles vão adquirir as luzes necessárias ${ }^{11}$. [grifo meu]

Assim, então, depois de inúmeros debates, os deputados se decidem por duas Faculdades, uma em Pernambuco e outra em São Paulo. A posição estratégica nordestesul era uma das formas de cooperar com a ideia de unidade imperial, afinal, como lembra Neder, (...) os juristas que tomaram tal decisão enxergaram com os olhos do passado (metropolitano) o futuro do Império; refletiram sobre a importância desta localização como sendo também uma estratégia de 'construção da nação"12. Aliás, como se dizia à época, um império em tamanhas dimensões e com representantes de todas as partes teria que compartilhar seus pólos de ensino e saber. Assim, as faculdades de Direito propiciariam mais um veículo motor para compor uma estrutura profissional e acima de tudo ideológica para a construção da nação e, por conseguinte, fortaleceriam as estruturas imperiais no Brasil. Por outro lado, não se pode esquecer, a dignidade de ser um cidadão brasileiro estaria vinculada à necessidade de projetar homens no seio intelectual nacional, o que fomentaria a identidade entre os pares e preencheria a lacuna do conhecimento emprestado do além-mar ${ }^{13}$.

10 Dallari, Dalmo de Abreu (2000). "O Brasil colonizado: raízes da sociedade e do Estado". In Mota, Carlos Guilherme. Viagem Incompleta. A experiência brasileira. A grande Transação, São Paulo: SENAC, p. 460.

${ }_{11}$ José Martiniano de Alencar. Sessão 28 de Agosto de 1823. In ANNAES DO PARLAMENTO BRAZILEIRO. Assembléa Constituinte.1823. Tomo 4. Rio de Janeiro: Typ. de H.J. Pinto, 1879. p. 183.

${ }_{12}$ Neder, Op. Cit., p.137.

13 Uma das falas que sintetizam estas ideias está no pronunciamento do deputado Almeida e Albuquerque: "é preciso tirar os brasileiros da penosa necessidade de irem mendigar luzes nos países remotos, para que a nação tenha filhos dignos dela, é indispensável facilitar-lhes todos os médios deles adquirirem conhecimentos; sem o que os homens pouco ou nada são...". Ver: Manuel Caetano de Almeida e Albuquerque. Sessão 27 de Agosto de 1823. In ANNAES DO PARLAMENTO BRAZILEIRO. Assembléa Constituinte.1823. Tomo 4. Rio de Janeiro: Typ. de H.J. Pinto, 1879, p. 169. 
Ancorados nas experiências transatlânticas, esses estadistas acreditavam que a utilidade da formação jurídica para a recente nação era indispensável "pela necessidade em que estamos de homens letrados e hábeis neste gênero de saber. (...). Todos sabem que para estes empregos é mister ter grande cópia de estudos de direito natural, público e das gentes, de política e economia política..."14. A necessidade de ilustração nacional estaria diretamente ligada ao conhecimento das leis e de sua funcionalidade no aparelho estatal, como já exposto, e o título superior, ao que um galgava o status de doutor, era o caminho legítimo, em muitos casos, para estar habilitado à construção das codificações da nova nação da América ${ }^{15}$.

Nesse sentido, a composição curricular dos cursos de Direito no Brasil ${ }^{16}$ não foi um tema meramente acadêmico. As discussões sobre os seus Estatutos já davam conta da importância e visibilidade que os cursos jurídicos teriam para o país ${ }^{17}$. Quais as cadeiras, quais as leituras necessárias e qual a linha jusfilosófica que esta formação superior iria levar, seria a marca espelhada de uma tentativa de síntese do pensamento dos dirigentes brasileiros. Contudo, não havia maneira de se criar algo original sem que o que fosse mais familiar tomasse a cena. Isso representaria a pedra inicial de maior domínio para conhecer o que aplicar ou o que rechaçar. Portanto, a inspiração coimbrã, menos que um grande incômodo, poderia servir de suporte filosófico e pedagógico para a consolidação dos Cursos Jurídicos. Assim, os Estatutos da Faculdade de Direito de Olinda e São Paulo, elaborados pelo Visconde de Cachoeira, desde 1825, guardavam em si a forte característica da transposição do que regia o ensino superior na antiga metrópole. Apesar de não ser uma cópia fiel, havia a preocupação, ao menos idealizada, com os pressupostos teóricos do ensino que estariam ali presentes, em boa medida, como os da Universidade de Coimbra.

A formação acadêmica no Brasil independente, desde os inícios de sua estruturação, esteve associada menos em promover uma circulação de ideias e uma formação de intelectuais que no estímulo por uma massa de profissionais burocraticamente engendrados ao aparato administrativo e político do Império. A

\footnotetext{
14 Luis José de Carvalho e Melo. Sessão 27 de Agosto de 1823. In ANNAES DO PARLAMENTO BRAZILEIRO. Assembléa Constituinte.1823. Tomo 4. Rio de Janeiro: Typ. de H.J. Pinto, 1879, p. $166-167$.

15 Ver Gauer (2001). Op. cit, p. 172 e ss. E também Carvalho, José Murilo de (2003). A Construção da Ordem. Teatro de Sombras, 3. Ed, Rio de Janeiro: Civilização Brasileira.

16 A criação dos cursos jurídicos no Brasil, instalados em São Paulo e Olinda, foi aprovada pela Assembleia Geral Legislativa em Agosto de 1826 e pelo senado em Agosto de 1827.

17 Sobre o tema conferir Bevilácqua, Clóvis (1927). História da Faculdade de Direito do Recife, Rio de Janeiro: Liv. Francisco Alves; Venâncio Filho, A. (1973). Op. cit.
} 
estabilidade e a unidade do jovem país estariam vinculadas a um preparo gestado e patrocinado pelo Estado. Portanto, promover o estudo do Direito no Império era uma missão de civilização, de conhecimento e de aprimoramento de seu próprio corpo administrativo, buscando a harmonia do deve-ser jusfilosófico com a garantia do desenvolvimento da sociedade civil. E os Cursos Jurídicos de Pernambuco e São Paulo levavam em si a atribuição de abranger uma grande gama de assuntos governamentais, sendo o mais eclético dos cursos superiores.

Nesse sentido, formar intelectualmente um bacharel era trazer as luzes para o Império. Ter uma formação superior no Direito denotava o vetor de ilustração nacional a médio e longo prazo. Ser um doutor advogado era um símbolo também de que o país progredia, que tinha conhecedores das suas leis, o que garantiria a boa funcionalidade do aparelho estatal. Portanto, as Faculdades de Direito que se estruturariam no Império nos anos seguintes as suas aprovações, foram reflexo dessa conexão entre a necessidade de ordem e o reconhecimento dela, através do conhecimento das leis que se tencionavam nacionais. A civilização espelhada através do doutrinamento de uma cultura jurídica própria foi uma das estratégias efetuada pelos estadistas do Brasil trazendo em seu bojo caracteres de racionalidade e de modernidade para as mentes nacionais que, como diziam, necessitavam das luzes.

Contudo, para que a engrenagem funcionasse desde os bancos do ensino superior até os mais altos postos de representação política e judiciária do país, era necessário eleger uma estratégia no ensino que conformasse as intenções primárias do Estado, discutidas desde a Assembleia Constituinte de 1823. Como antes esclarecido, os Estatutos do Visconde de Cachoeira representaram um suporte de fundamental importância para que essas diretrizes pudessem ganhar sentido. Era necessário pensar quais as cadeiras necessárias para formar esse futuro bacharel, projetado para servir ao Estado, bem como qual corrente filosófica deveria orientar aos alunos dos cursos jurídicos e, por fim, quem poderia ministrar essas aulas para os alunos de Olinda e de São Paulo.

Nesse viés, além de ser considerado um curso a serviço do país, o Curso Jurídico para o Império deveria se equilibrar em uma zona de conforto entre o passado jurídico considerado arcaico e colonial e a identidade normativa e positiva nacional. Assim sendo, esses mesmos estadistas notaram que era impossível criar uma nova estrutura sem que a referência de ensino do passado fosse utilizada como esteio. Portanto, a inspiração coimbrã, menos que um grande incômodo, poderia servir de suporte filosófico 
e pedagógico para a consolidação dos Cursos Jurídicos de Pernambuco e São Paulo.

Ainda que houvesse, por parte dos organizadores dessa matriz ideológica e jurídica do país, algum receio em utilizar as bases lusas de ensino ou que se pensasse que poderia ser um caminho para ratificar o poderio ideológico da antiga metrópole, não parece que ao fim e ao cabo tais receios abarcassem o sentido geral entre os parlamentares sobre o ordenamento dos cursos. Em realidade, ao que muito pôde custar admitir àquele momento, era possivelmente a afinidade tanto com a regulação dos cursos de Coimbra como com as Ordenações Filipinas que garantiriam a habilidade para recompor, unir, dissociar e excluir o que lhes parecia arcaico, antinacional ou pouco liberal.

Os tons mais típicos, pelo que aponta a historiografia balizada no tema do ensino jurídico do período ${ }^{18}$, que caracterizariam o ensino no país independente, se orientavam pelo rechaço à predominância nos estudos do Direito Romano, deveras enfatizado no ensino lusitano e que, para os estudos nacionais, era mais uma cadeira para a erudição discente, segundo alguns parlamentares, do que uma necessidade para a constituição do conhecimento de suas leis nacionais. Assim, a cadeira de Direito Pátrio, por exemplo, era considerada ensino apropriado às novidades dos tempos e à nova configuração política que se vivia. Apesar de não haver uma história jurídica no país que estimulasse os alunos a observar toda a trajetória do uso das leis em âmbito nacional, o tema do Direito Pátrio constituía-se como uma das principais necessidades de atenção e predicação para os futuros bacharéis. E essa foi a tônica dos Estatutos de Cachoeira que prevaleceram, a princípio até 1831, mas em sua essência durante boa parte do século XIX, quando Couto Ferraz, em 1854, e Leôncio de Carvalho, em 1879, atualizaram-na com reformas de algumas das normas do citado regimento ${ }^{19}$.

De maneira geral, o curso de direito trazia uma configuração, em suas nove cadeiras, bastante apegada à lógica coimbrã. Se por uma parte incorporavam Economia Política e Teoria e Prática do Processo adotado pelas Leis do Império, por outra convivia Direito Público Eclesiástico com Direito Natural e Direito Público. Ou seja, os Estatutos do Visconde eram também uma expressão da ambígua e até eclética base jurídica e política

\footnotetext{
${ }^{18}$ Bevilacqua, Clóvis (1927). História da Faculdade de Direito do Recife, Rio de Janeiro: Liv. Francisco Alves; Venâncio Filho, A. (1973). Op. cit.; Adorno, Sérgio (1988). Os Aprendizes do Poder. Bacharelismo liberal na política brasileira, Rio de Janeiro: Paz e Terra; Koerner, Andrei (1998). Judiciário e Cidadania na constituição da República brasileira, São Paulo: HUCITEC-USP, entre outros.

${ }^{19}$ Sobre o tema, afirma Venâncio Filho que "Os Estatutos do Visconde de Cachoeira representam, assim, a matriz de onde se originaram os textos regulamentares do nosso ensino jurídico, perdurando muitos dos seus princípios até a República". Ver Venancio Filho, A. (1973), Op. cit, p.36.
} 
a que os bacharéis do Brasil teriam que se ambientar.

Manteve-se o arcaísmo nas relações com a igreja e o Estado, mas também se absteve de ressaltar o passado colonial, quando do Direito Romano é tirada a centralidade, pois que se relacionava diretamente à formação jurídica lusa. Por outro lado, como afirmava os Estatutos, “(...) é o Direito Pátrio um corpo formado por instituições próprias deduzidas do gênio, e costumes nacionais, e de muitas Leis romanas já transvertidas ao nosso modo..." ${ }^{20}$.Vale considerar que a referência do Visconde de Cachoeira sobre a relevância dos estudos de Direito Pátrio se entrecruzava também com uma tensão: se havia uma valoração do ensino da história do Direito através desta cadeira, isso significava que os futuros bacharéis teriam que estudar o seu próprio passado colonial, já que em matéria de constituição de uma história nacional se carecia totalmente de dados.

Assim, mesmo havendo a contextualização às linhas doutrinais em voga à época, a base estatutária dos cursos jurídicos no Brasil seguiu demonstrando uma forte inspiração aos cursos da faculdade de Direito de Coimbra. As cadeiras mais clássicas, como a de Direito Natural, seguiam instruídas para as leituras de Grócio ou de Wolff, e a de Direito Pátrio, para Mello Freire e outros tantos que também compunham os regimentos lusitanos. Ainda assim, merece ser destacado que toda essa estrutura básica modular idealizada como a melhor forma de educar um bacharel, não pode negar o caráter liberal e constitucional que os estadistas do império tentavam impregnar em seus próprios cursos jurídicos. A cadeira de Economia Política, por exemplo, foi considerada uma inovação à época, antecipando-se inclusive à França, e se direcionavam os docentes a ministrarem com base em Ricardo, Malthus ou Smith.

De todos os modos, o meio acadêmico era uma porta de entrada para que esses jovens estudantes pudessem se preparar para o campo de atuação que o Estado lhes garantiria, com alguma confiança, aceder. Nesse sentido, São Paulo e Pernambuco atendiam à dita demanda. Mesmo os seus formandos necessitassem de um emprego para realmente aprender o ofício ao qual foram preparados por pelo menos 5 anos, esse processo de consolidação de um grupo de intelectuais que pensava a justiça e o ensino como fulcrais para a conformação estatal seria gerado no decorrer do século XIX e, vale recordar, inúmeros estadistas do Império e posteriormente da república no Brasil sairiam

\footnotetext{
${ }^{20}$ Estatutos da Faculdade de Direito de Olinda e São Paulo de Visconde de Cachoeira. Em: Criação dos Cursos Jurídicos no Brasil (1977). (Documentos Parlamentares). Brasília/Rio de Janeiro: Fundação Casa de Rui Barbosa. Ver também: Bevilacqua, C. (1927). Op. cit.
} 
desse ambiente acadêmico, comprovando que, de algum modo, não seria desapontado o ideal ansiado por aquelas primeiras reuniões constituintes: formar juristas-políticos aptos para atuar em uma ampla gama de tarefas na administração estatal.

Nesse sentido, se pode perceber o quanto os laços referenciais com a exmetrópole foram importantes para a confecção do sistema político e jurídico no Brasil. Essa influência, que percorre obviamente mais que os tempos reformadores de Pombal, não teve caráter meramente coadjuvante. Como visto, o intuito dos estadistas no recém formado Império era o de promover algo diverso em alguma medida, mas eles não empreenderam uma sistematização em seus Códigos e em seu aparelho funcional judiciário que destoasse do que aprenderam em séculos. Portugal tampouco tinha um sistema igual, já havia bebido também doutras fontes e o Brasil não esteve alheio a isso. As permanências no que tange a manutenção das Ordenações Filipinas podia ser uma primeira indicação, mas havia outras. Seguiu-se com a lógica do aprimoramento técnico e acadêmico como componente essencial para a gestão do aparato judicial, também, ainda que, olhando para França ou para Alemanha, construiu normativas legais que já haviam passado pelo olhar lusitano, como o Código Criminal de $1830^{21}$.

A elite unificada diante do princípio de que era necessária a centralização e a burocratização do aparelho estatal conseguiu que a ocupação de cargos no Estado fosse o ponto de fusão e de acordos internos visando a estabilidade dos interesses de grandes proprietários e exportadores agrários do país. Portanto, dentro da inspiração liberal, 0 agente interlocutor dessas mesclas de interesses privados e públicos, dotado de uma formação técnica e arauto do Estado, seria o conhecedor dos Códigos. Era ele quem manipularia toda a ação de justiça, já que tinha eminentemente uma formação profissional jurídica.

A base formadora desse corpo de profissionais, não se podia negar, advinha de matriz colonial e seguia colonizando e marcando as matrizes filosófico-jurídicas de quem foi, há pouco, um Reino Unido. Até meados do século, ainda podia-se contar com políticos e magistrados da geração de 1790, formada em Coimbra. Quando o país conscientizavase como independente também se inauguravam os Cursos Jurídicos, que tinham em suas próprias estruturas orientações filosóficas e políticas destoantes entre si.

No caso da trajetória política que o Império seguiu, entre a onda liberal e o regresso conservador, para ambos os casos, houve uma matriz ocidental colhida da parte

\footnotetext{
${ }^{21}$ Vale conferir a Introdução de Carvalho em: Vasconcelos, Bernardo Pereira de (1999). Bernardo Pereira de Vasconcelos. Org. e Introdução. De José Murilo de Carvalho, São Paulo: Ed. 34.
} 
ibérica, católica e escolástica. Centralista, monárquica e amante das leis e da burocracia, essa matriz chegou não somente pela administração colonial e suas práticas pelo território americano, mas teve na filosofia da chamada Segunda Escolástica, mesclada às luzes pombalinas, sua associação ao espírito moderno e liberal que circulava na Europa. A associação entre política e administração pública gerou a necessidade de formar, dentro de sua filosofia, um corpo de funcionários aptos a mover e promover o Estado.

Nesse sentido, o direito e o Estado se conectavam e o conhecimento do primeiro era situação sine qua non para ser incorporado às malhas estatais. O bacharel em Direito trazia de Coimbra o esteio intelectual e técnico imprescindível para seguir gerindo o controle português. Dessas marcas o Brasil não se livraria tão cedo. Como antes matizado, formar-se-ia no além-mar uma grande parte dos estadistas que fomentariam a independência e que posteriormente ordenariam o jovem país.

Seguiu-se a tradição, temperada aos ecos franceses, ingleses e norteamericanos de modernidade, cientificismo e liberalismo. Seguiu-se o centralismo, o unitarismo quase absolutista e um ecletismo mitigado mesclado à atualidade dos tempos. Ainda que se formasse um pólo próprio de conhecimento, alternativa clara para uma construção de identidade adaptada às necessidades do Estado independente, o Brasil imperial e seus Cursos Jurídicos continuavam em marcha coimbrã ainda que incorporados a novos temas. Mais que plasmar da universidade lusa seu pedagogismo herdado dos tempos pombalinos, os próprios Estatutos brasileiros denotavam uma preparação política para velhos fins: manter a lógica centralista do Estado e a ordem através da lei e de sua aplicação. Pernambuco e São Paulo foram herdeiros dessas marcas, formaram um corpo político e administrativo que o país necessitava.

"Sendo obra de homens e [?] e executadas pelos homens", as leis imperiais no Brasil deveriam ser reflexos de boas ações do governo em prol de seu povo e ao mesmo tempo ser o canal para o ordenamento do Estado para o bem público. Para tanto, era necessário preparar os que iam manejar as leis em proveito desse bem. A sobrevalorização do bacharel, e de sua formação foi um status construído em meio ao processo de erguimento do Brasil enquanto espaço autônomo. Contudo, e ainda assim sendo, essa gestão já havia sido conquistada antes, desde o período pós-pombalino. Em realidade, a marca dessa valorização da figura do bacharel estaria nos mesmos Estatutos pombalinos para a Universidade de Coimbra.

Pode-se dizer que desde ali, da reformatação que o ensino secundário e superior 
tomou desde meados do XVIII, já se tinha na colônia o intercâmbio de ideias e da centralidade na figura do conhecedor das leis. Com isso, não se quer por em relevo que essa tendência na cultura política e jurídica surgiu nesse momento e tampouco que foi mérito apenas de Pombal e de seus sucessores. O que se quer dizer, sim, é que essa valoração da figura preparada, conhecedora das leis, foi introduzida e matizada nos trópicos lusos, graças, é claro, ao seu colonizador e que em grande medida se pode inferir que essa tradição fora gestada muito antes da família real cruzasse o Atlântico ou ainda de que seus laços fossem desfeitos.

Por outro lado, é importante compreender que, além de reconhecer que esse processo tem uma herança marcada de longa data, ela não se desfez após a ruptura política com a antiga metrópole. O Brasil Império não apenas manteve o rei de sangue português imperando sobre o país, como também se esmerou em mudar, aperfeiçoar ou manter o que poderia servir ao aparato estatal. O Poder judiciário não estaria fora dessa lógica, por suposto. Ter o título de bacharel era ser político, funcionário do Estado, Presidente de Província, Juiz de Direito, desembargador, enfim, uma gama de possibilidades das que tanto os ricos fazendeiros como os medianos comerciantes estariam atentos para lograr um posto de comando nas malhas do poder.

Nesse processo, as heranças lusas poderiam ser observadas de diversos matizes. O mais geral era a conexão curso superior em Direito e emprego público, amplamente reconhecido pela historiografia, porque deveras debatido entre os estadistas. Essa prática não era uma solução genuína, era uma alternativa plasmada da realidade lusa. Quantos filhos de ricos fazendeiros existiam e queriam mais que administrar as terras dos pais, tanto mais estariam ocupando as cadeiras dos cursos jurídicos em Coimbra, a princípio, e posteriormente em terras nacionais. Ao que desejava mais que posse e prestígio local, teria que galgar um diploma em terras lusas para conectar sua posição local com a intercontinental. Trabalhar para o governo, circular entre seus diferentes domínios metropolitanos como seu representante forjou uma mentalidade que ratificava a necessidade do título, em plano geral, e mais ainda possibilidades se fosse 0 de bacharel em direito.

Assim sendo, a relação entre a funcionalidade da formação em ciências jurídicas e sociais ${ }^{22}$ e sua associação a ampliação ou acesso ao prestígio social e político no país,

\footnotetext{
${ }^{22}$ Vale destacar um dos artigos que compunha o Capítulo I dos Estatutos de Cachoeira, quando tratava da necessidade de o jovem ingresso no curso jurídico ter conhecimentos, entre eles " $4{ }^{\circ} \mathrm{O}$ estudo de Retóri ca é também indispensável aos que se dedicam à Jurisprudência, porque o advogado deve pelo menos saber a
} 
seria uma marca que percorria as veias luso-brasileiras.

A elite política que vai existir no Brasil não será homogênea e tampouco dentro dela se encontrará a harmonia de intenções para o que seria o progresso iluminado do XIX. Contudo, há de se lembrar que, o tema da formação, da raiz comum na constituição do pensamento político e jurídico do país perpassava o mesmo ancoradouro: uma elite política que tendia à manutenção dos status e do privilégio que já levavam anos em suas mãos, e sob essas mesmas máximas éticas, ansiadas pela própria sobrevivência e manutenção do poder social, conseguiriam se unificar quando, dos momentos mais conjunturais de tensão ou de sacrifícios políticos e ideológicos, colocava-se em xeque seus valores essenciais. Portanto, as vias da educação, ocupação e carreira política ${ }^{23}$ foram de fundamental importância para estabilizar os eixos destoantes objetivando ao que os dirigentes do poder estatal visavam conservar: o latifúndio e o trabalho escravo.

De momento, se percebe que a educação era uma promotora da ocupação de cargos governamentais o que poderia ou não gerar uma vida política no Império. A exemplo da pátria metropolitana, o ingresso ao aparelho estatal era sinônimo de uma vida estável, bem colocada socialmente, reflexo de seu êxito político e, em alguns casos, econômico $^{24}$. Vale recordar, entretanto, que a característica geral do ensino da elite política seria a preferência por uma carreira que facilitasse o acesso à vida política, ou seja, o direito. Ademais, principalmente na segunda metade do XIX, para aceder a um cargo político a instrução seria fundamental, ainda que fosse somente o ensino secundário, como era considerado o ensino das escolas militares, sendo que antes desse período, se podia chegar ao cargo de senador um homem sem formação, mas com prestígio político local.

Portanto, no Brasil, a valorização da formação superior pela via jurídica se tornou a tônica pela qual o país ordenaria sua missão centralizadora e ordenadora do Estado. O fenômeno do bacharelismo, deveras estudado por historiadores e estudiosos de história e

eloqüência do foro; e a arte de bem falar, e escrever muito necessária é aos que houverem de ser Deputados nas assembléias, ou empregados na Diplomacia...". Estatutos da Faculdade de Direito de Olinda e São Paulo de Visconde de Cachoeira. [grifo meu].

${ }^{23}$ Ver: Carvalho, J. M (1999). Op. cit, p. 35. O autor observa que "em geral, a homogeneidade ideológica funciona como superadora de conflitos intra-classes dominantes e leva a regimes de compromisso ao estilo da modernização conservadora".

${ }^{24}$ Carvalho observa, tratando do tema em Portugal, que a formação de sua elite política foi distinta de outras nações européias, pois tinha uma nobreza dependente dos cargos políticos e do aparelho burocrático para manter status e sobreviver. Abordando o Código Afonsino, de 1446, como o primeiro redigido em Europa, destaca que os juristas e magistrados exerceram um papel de grande importância na política e na administração portuguesa e brasileira: "tratava-se de uma elite sistematicamente treinada, sobretudo graças ao ensino do direito na Universidade de Coimbra". Carvalho, J. M (1999). Op. cit, p.36. 
filosofia do direito, se consagrava como veículo para a legitimidade do Estado e sinônimo de civilização ${ }^{25}$.

Com o tempo, a lei dos homens se aperfeiçoaria em favor dos poucos homens que as representavam. Mas, esse fato não é de grande novidade na historiografia. Interessa, pois, saber afinal o que destas leis, obra de homens, estaria sendo movimentado, praticado e moldado ao dia a dia dos tribunais. Entre a necessidade de preparo e a sua efetividade nas parcas estruturas judiciárias do XIX certamente havia um largo fosso. Por isso a necessidade em entender a importância da figura do bacharel: sua formação, a cultura política que o envolvia à época, assim como as prioridades do Estado quanto a estrutura do judiciário. Estes são eixos essenciais para que as práticas jurídicas e suas contradições sejam conhecidas e reconhecidas no trabalho de investigação que se está realizando. Com este estudo, se pretende dar seguimento as pesquisas em curso, justamente para contribuir para o conhecimento das práticas jurídicas desses bacharéis oitocentistas, problematizando, a partir de sua rotina no espaço cotidiano de trabalho, as relações entre a justiça, o entorno social e o poder no Império do Brasil.

\section{Fontes e Bibliografia}

\section{Fontes Consultadas:}

ANNAES DO PARLAMENTO BRAZILEIRO. Assembléa Constituinte.1823. Tomo 4. Rio de Janeiro: Typ. de H.J. Pinto, 1879.

Anais da Assembléia Constituinte de 1823. Versão Eletrônica. Site da Câmara dos Deputados.

Código Criminal do Império do Brazil de 1830. Versão Eletrônica. Site do Planalto do Brasil.

Projeto de Regulamento ou Estatuto para o Curso Jurídico Creado pelo Decreto de 09 de Janeiro de 1825, organizado pelo Conselheiro de Estado Visconde de Cachoeira. Apud. MOTA, C. G (2006). (coord.). Os Juristas na Formação do Estado Brasileiro. Vol I. São Paulo: Quartier Latin. (Coleção Juristas Brasileiros).

RELATÓRIO DO MINISTERIO DA JUSTIÇA APRESENTADO A ASSEMBLEIA GERAL

\footnotetext{
${ }^{25}$ Silva (2003). Op. cit.
} 
LEGISLATIVA (1858). Rio de Janeiro: Typ.Nacional.

\section{Bibliografia citada:}

Adorno, Sérgio (1988). Os aprendizes do poder. Bacharelismo liberal na política brasileira, Rio de Janeiro: Paz e Terra.

Bevilácqua, Clóvis (1927). História da Faculdade de Direito do Recife, Rio de Janeiro: Liv. Francisco Alves.

Carvalho, José Murilo de (2003). A Construção da Ordem. Teatro de Sombras, 3 Ed, Rio de Janeiro: Civilização Brasileira.

Dallari, Dalmo de Abreu (2000). "O Brasil colonizado: raízes da sociedade e do Estado". In: Mota, Carlos Guilherme. Viagem Incompleta. A experiência brasileira. A grande Transação, São Paulo: SENAC.

Dias, Maria Odila da Silva (1968). "Aspectos da Ilustração no Brasil". In: Revista do Instituto Histórico e Geográfico Brasileiro, n. 278, Rio de Janeiro, p.105-170.

Gauer, Ruth M. Chittó (2001). A Construção do Estado-Nação no Brasil, Curitiba: Juruá.

Koerner, Andrei (1999). Habeas-corpus, prática judicial e controle social no Brasil (18411920), São Paulo: IBCCrim.

Neder, Gizlene (2007). Iluminismo Jurídico-penal Luso-Brasileiro. Obediência e submissão, RJ: REVAN.

Perrot, Michelle (1999). Os excluídos da História: operários, mulheres e prisioneiros, Rio de Janeiro: Paz e Terra.

Silva, Mozart Linhares (1997). Do Império da lei ás grades da cidade, Porto Alegre: EDIPUCRS.

Silva, Mozart Linhares (2003). O Império dos Bacharéis, Curitiba: Juruá.

Slemian, Andréa (2006). Sob o Império das Leis: constituição e unidade nacional na formação do Império do Brasil (1822-1834). Tese (Doutorado em História) - Universidade de São Paulo, São Paulo.

Sobrinho, Barbosa Lima (1979). Pernambuco, da Independência à Confederação do Equador, Recife: Conselho Estadual de Cultura.

Spinosa, Vanessa (2011). Uma Justiça para o Estado: formação jurídica e produção legislativa no Brasil do período tardo-colonial à Regência (1750-1841), Trabajo de Grado (História), Universidade de Salamanca.

Vasconcelos, Bernardo Pereira de (1999). Bernardo Pereira de Vasconcelos, Org. e introd. De José Murilo de Carvalho, São Paulo: Ed. 34. 
Venâncio Filho, Alberto (1973). "A Criação dos Cursos Jurídicos, símbolo da independência nacional". In RBIHG, vol. 299, Rio de Janeiro: Departamento de Imprensa Nacional, abr/jun.

Recebido para publicação em março de 2011. 